\title{
Virtual Goods Markets and Economy in China: A Historic Account
}

Mann (Michael) Zhang

Eastern New Mexico University

Follow this and additional works at: https://digitalcommons.uri.edu/mgdr

Part of the Anthropology Commons, E-Commerce Commons, Economics Commons, Marketing Commons, Other Business Commons, and the Sociology Commons

\section{Recommended Citation}

Zhang, Mann (Michael) (2016) "Virtual Goods Markets and Economy in China: A Historic Account," Markets, Globalization \& Development Review. Vol. 1: No. 1, Article 7.

DOI: 10.23860/MGDR-2016-01-01-07

Available at: https://digitalcommons.uri.edu/mgdr/vol1/iss1/7

This Article is brought to you for free and open access by DigitalCommons@URI. It has been accepted for inclusion in Markets, Globalization \& Development Review by an authorized editor of DigitalCommons@URI. For more information, please contact digitalcommons-group@uri.edu. 


\section{Virtual Goods Markets and Economy in China: A Historic Account}

\section{Markets, Globalization \& Development Review}
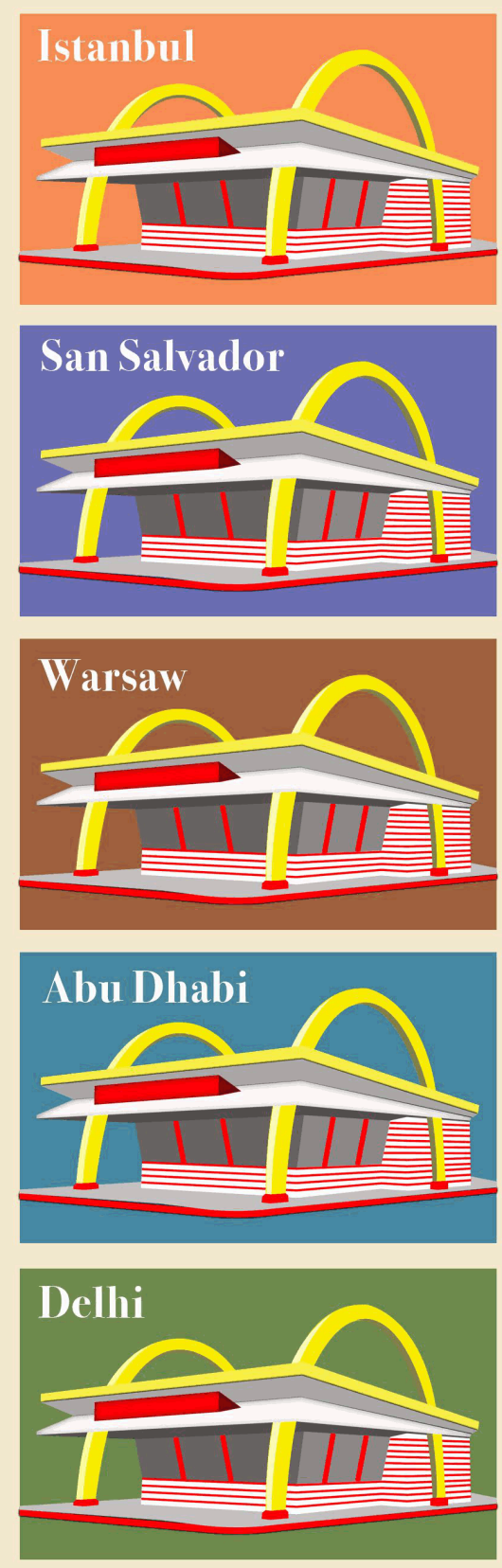
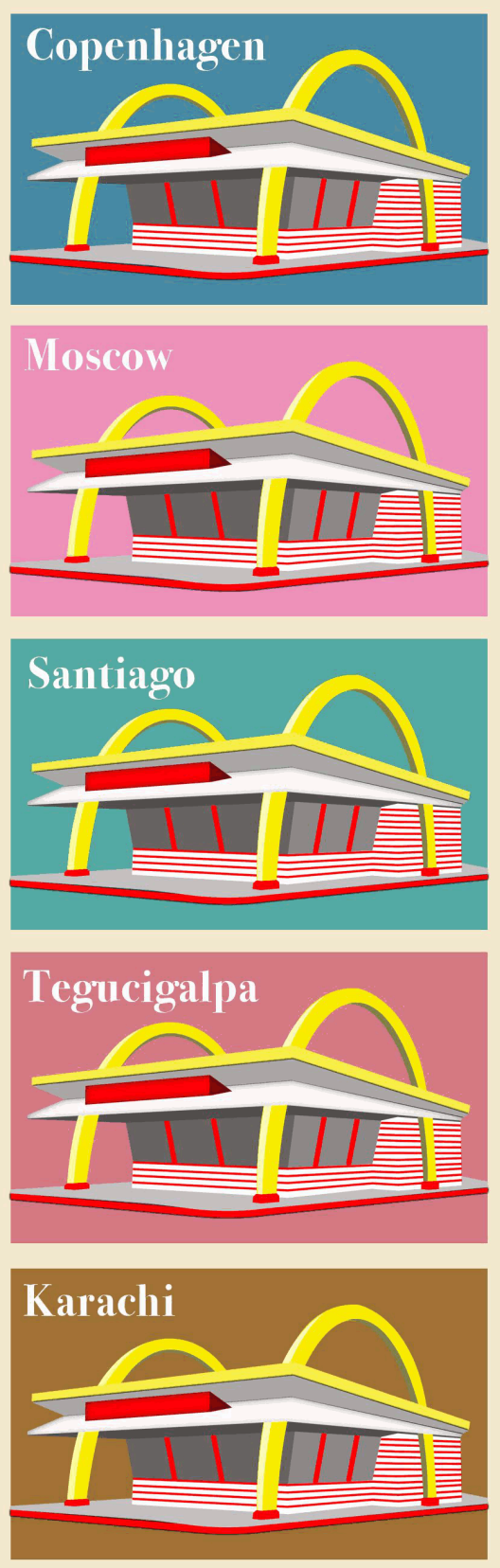
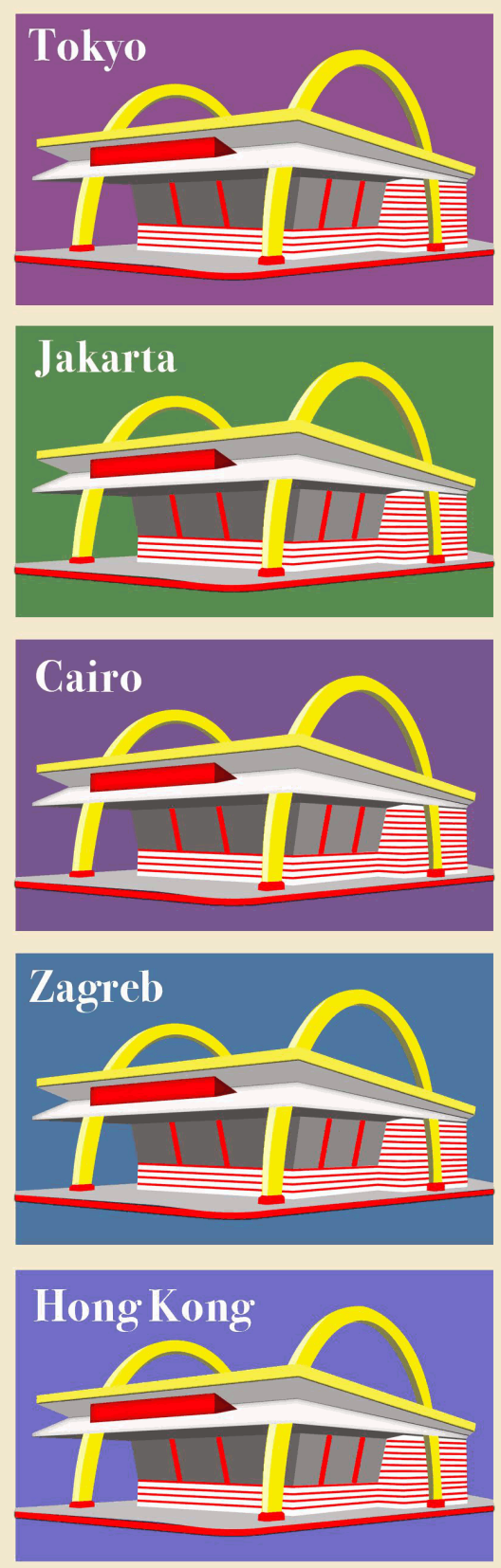

This article is available in Markets, Globalization \& Development Review: https://digitalcommons.uri.edu/mgdr/vol1/ 


\section{Virtual Goods Markets and Economy in China: A Historic Account}

\section{Introduction}

Virtual goods market is booming in many parts of the world. Examples of such market include multiplayer online games and virtual gifting. The fast rate of growth of virtual consumption in some developing countries, especially China, has made such countries the leading players in the emerging global virtual goods market. For instance, the market for virtual goods in China had reached $\$ 5$ billion by 2009, five times larger than that in the United States (Boykoff 2010). By 2012, China had the world's largest market for virtual goods (Hawkins 2012). By 2014 China's virtual goods revenue was estimated to be $\$ 7.4$ billons (statista 2012). Indeed, as Chayka (2014) notes, the emergent virtual economy is dominantly nonwestern and primarily Asian in character:

For all of its social-network start-ups, North America falls far behind other areas of the world in mobile-gaming [virtual economy] revenues. Asia is home to the vast majority of mobile gaming payments, with $\$ 10$ billion in 2014 , over four times as much volume as North America... This [virtual] economy of the future will be as digital as possible, increasingly non-Western, and contained within easily accessible smartphone ecosystems. Its merchants will rigorously mete out content over time to keep customers engaged and the money flowing. While we might not be paying for digitalonly groceries instead of actual produce any time soon, all economies will soon be, to some extent, virtual.

Research on China's virtual goods markets, however, is relatively limited. Given the important roles China is playing in the emerging global virtual and real economies and the distinct cultural-economic-political context in China, an understanding of the virtual goods market in the context of China is central for understanding this new, future form of economy. This paper documents the growth of virtual goods market in China and explores the aspects of China's reality that resonate well with or hinder such growth, and draws out some implications for marketing strategies and actions.

\section{Growth of Virtual Goods Market in China}

Chinese consumers were first exposed to digitized virtuality when video arcades and video game consoles were introduced to the Chinese market 
in the 1980s. Later, Massively Multiplayer Online Role-Playing Games (MMORPG) got their foothold in China around 2000 and soon exploded in China's market. In just two years, from 2002 to 2004, the MMORPG market in China tripled from $\$ 149$ million to $\$ 517$ million (Ren and Yang 2004). The year 2004 was a turning point in the development of virtual goods market in China. Before 2004, the business model was primarily focused on the pay-to-play or monthly subscriptions to MMORPGs (e.g., MMORPG game - King of Kings) (NDC China 2009). In 2004, when the MMORPG The Great Merchants was released to the market with free game access, many companies, such as ShanDa Games, followed suit and turned to the 'freemium' (free initially, then pay for advanced levels) business model with virtual goods transactions (NDC China 2009). In 2007, the MMORPG market in China reached $\$ 1.3$ billion with over $70 \%$ of games released with free access (NDC China 2009), and in 2014, it reached $\$ 9.7$ billion (Wei 2014). It is estimated that 5 to 10 percent of gamers in China pay real cash for virtual goods. These paying gamers, however, tend to be high-spenders and their devotion to the games helps support the other 90 percent of gamers that play for free (Kwang 2011).

China's virtual goods market in online chatting (such as the $Q Q$ messaging platform) is even bigger, dwarfing the virtual goods market in MMORPG. Tencent, China's largest Internet service portal launched in 1998, offers diverse internet services such as QZone and Pengyou social networks, Weixin mobile chat (also called WeChat), its own Weibo microblog service, online games and more. For Tencent, the majority of its massive virtual goods revenue comes from the popular $Q Q$ instant messaging service that unites everything together (Su 2010). Most of the $Q Q$ users are using the free basic service such as text chat, voice chat, and video chat. Over 30 million $Q Q$ users, however, pay to get enhanced services such as changing $Q Q$ avatars (from the default versions that are offered free) or buying clothes for their avatars, as well as through exchange of virtual gifts.

From 2007 onwards, the success of the avatar Ailin Graef, a female and Chinese-born "first millionaire in virtual world" (in the game currency) in Second Life inspired Chinese firms to begin to develop Chineseversions of $3 \mathrm{D}$ virtual worlds. Among the Chinese versions of virtual worlds, the most famous ones are HiPiHi, Novoking, and Uworld. By 2009, however, all of these virtual worlds were on the verge of going out of business. HiPiHi only had 48,000 registered users, Novoking had 10,000 registered users, and Uworld had only 1000 registered users (Zhang et al. 2010). Chen (2009) found that 3D virtual worlds, such as HiPiHi and Second Life, are platforms for user-generated content, which requires 
creativity and skills of design and even programming. Thus, unlike regular online games that are fun-based, 3D virtual worlds have high threshold for users and only attract hardcore players, and most casual users soon lose interest.

With the emergence of casual games on social networking sites (e.g., Happy Farm on Kaixin) and more advanced mobile phones that can access these games, a new virtual goods market has been created in recent years, but the revenues generated from the social games have been modest (Boykoff 2010). On the other hand, free social games on social networking sites - featuring 2D interface, easy access, and play that appeal to Chinese consumers - have seen a rise in popularity among Chinese consumers. In one industry report, 88 percent of those surveyed said they played social network-based games (Niko Report 2010). For instance, Happy Farm (a Farmville imitator) became, for a while, China's most popular social game, with 23 million daily usages (Su 2010).

By 2012, China had the world's largest virtual goods market, with revenue of $\$ 10$ billion per year (Hawkins 2012). In what follows, a historic analysis is presented, examining the impacts of macro-environmental factors leading to such rapid, massive and pervasive rise in virtual goods market in China.

\section{The Context of China's Virtual Goods Market}

During the period that China became the largest virtual goods market in the world, the Chinese society has been in a state of rapid transformation. The characteristics of this period include the post-1980 one-child policy, rapid socioeconomic changes, and 'the victory of materialism' (Rosen 2004). Chinese traditional cultural ideology faced the challenges arising from the increasingly visible Western consumption culture, with its emphasis on freedom of choice, especially in consumption (Friedman and Friedman 1980), which in turn influenced the Chinese consumers' online and offline consumer behaviors.

\section{Changes and Uncertainties in China's Economic Landscape}

Following the economic reforms initiated in 1979, China has steadily shifted from a planned economy to a market economy, and emerged as a major global economic power, with economic growth averaging nearly $10 \%$ through 2014 (Morrison 2015). Based on Purchasing Price Parity (PPP), China is now the largest economy in the world (Morrison 2015).

With a massive rise in disposable personal income over the years, from 343 yuan in 1978 to 28,844 yuan in 2014 (Trading Economy 2015), a growing portion of discretionary household income has been spent on leisure services, and the priority has shifted from the products of utilitarian 
nature to product of hedonic nature (Fan 2002), especially for the younger generation (Chu and Ju 1993). This younger generation of Chinese consumers are traveling the world, drinking Starbucks coffee, using Estée Lauder cosmetics, and engaging with virtuality in multiple ways. The theory of cluster consumption states that consumption does not change marginally or linearly; instead, it takes a discontinuous form, requiring leaps to new consumption clusters (deVries 2008; Dholakia 2012). In case of virtual consumption, consumers have a choice to purchase the virtual goods on a laptop or desktop computer, or on a smartphone or tablet, allowing virtual consumption anytime, anywhere. China has more smartphone users than US, Brazil, and Indonesia combined, over 816 million total in 2015, which includes over 170 million on its $4 G$ network and 223 million on 3G (Perez 2015). This trend is expected to continue - 4G smartphone connections in China would reach one billion by 2020 (Perez 2015).

The Chinese government has also recognized the importance of meeting the consumer demands of Chinese consumers, encouraging both local and foreign companies to participate in the efforts (Dholakia, Reyes and Zhang 2013). With the development of Internet and online banking in China, new kinds of payment methods have emerged to help users to get around constraints such as lack of credit cards, the most popular payment in advanced countries. For instance, Alipay is the leading online payment company in China with over 350 million registered users (Rao 2015). Alipay allows consumers to make payment online via their bank accounts, prepaid cards, or even make mobile and telephone payments, without having to use credit cards.

The dramatic effects of the economic reforms are also evident in the emergence of advertising and influx of multinational companies into China. Radio commercials appeared in China for the first time in January 1979, and in March of the same year, the first TV commercials appeared (Anderson 1984). KFC entered the Chinese market in 1987 (Cho 2009). China's admission to the World Trade Organization (WTO) in 2001 was another mark of economic growth and globalization of China's economic landscape. The large Chinese market has attracted a steady stream of foreign investments and foreign firms are expected to reshape the competitive space (Chan, Cui and Zhou 2009; Fang and Yen 2006; Leung and Chan 2006). Exposure to international products and services, the cultural influences brought by the multinational companies, and advertisements on radio and TV have introduced the modern lifestyle to the Chinese consumers. For example, Lin and Wang (2010) noted the subtle changes in cultural values and advertising strategies visible in 
Chinese commercials which emphasize youth and modernity appeals, and reflect westernization.

On the other hand, however, there have been continuous economic uncertainties over the years since the economic reforms of 1979. These include overdependence on exports as the economic driver, serious housing bubble problems (Barth, Lea and Li 2012), an inefficient banking system that "lacks the ability to ration and allocate credit according to market principles" (Morrison 2012), aging and 'graying population' problem that resulted from the one-child policy of 1980, lack of an adequate pension system, and the sharply rising costs of health care (Morrison 2012). The International Monetary Fund (IMF) projects that China's real GDP growth will slow to $6.8 \%$ in 2015 and to 6.3\% in 2016 (Morrison 2015). Therefore, the precautionary motive for saving and being frugal has been strong among Chinese consumers. For example, the high cost of buying consoles and games (e.g., Lenovo CT510 priced at $\$ 600$ when it was launched in 2004) is what made online gaming a really appealing option to Chinese consumers (Becker 2004). The possibility is real that the wide range of economic uncertainties may jeopardize consumption spending in general (Raquel Castaño 2015), which may include spending on virtual consumption.

\section{Changes in Political Policies and Legislation}

Chinese consumers' lives have been changed tremendously by policy reforms from late 1970s to 2010s. During this period, China has transformed politically from the legacy of Mao and imperialistic heritage (Lieberthal 1995) to what some researchers (e.g., Ogden 1995) describe as both the largest communist country and the fastest growing capitalist country that seeks "continuity with, as well as a departure from, the socialist legacy and cultural tradition of the past, and integration with, as well as resistance to, global capitalism" (Yu 2009, p. 6).

Before the reform in 1979, most Chinese consumers were assigned to a danwei, or work unit. In socialist China, the danwei, created on the concept of space of collectivism and egalitarianism, was "simultaneously the spatial building block, the locus of daily life, and the mainspring of social identity in the Chinese socialist city" (Hill 2005). The danwei not only provided its members with income, but also was "omnipotent in distributing every consumer product" (Yang 2005), including social goods such as housing, medical care, and day care and schooling, and consequently provided to its members identity and "ability to participate in wider society" (Bray 2005). The economic reform, especially the rise of private economy in China since 1979, has considerably diminished the danweis role in the construction of Chinese consumers' identity - as person who is a member 
of a work unit or a production cell - and afforded the opportunity to the Chinese consumers, as individual agents in society, to create their own identities (Bray 2005).

Family dynamics in China have also been changing along with the one-child policy and related legislations introduced between 1978 and 1980. A general decline in family size has been accompanied by changes in family life cycle. On the one hand, the one-child policy enhanced the consumption power of the only child, as "little emperor/empress" in the family, with the parents and grandparents concentrating their financial resources on the one child (Woronov 2002). On the other hand, it posed a serious social problem characterized as the "4-2-1 phenomenon", where the 'only' children, when they grew up and started working, had to provide the financial support for two parents and four grandparents. Even with high savings rates, it seemed that the younger generation was not able to afford such a burden (Economist 2012). Indeed, to reinforce the sense of filial obligation among the youth, even legislation was passed to support traditional filial values (Ikels 2006).

When Internet was first introduced to China in 1994 (Warschauer 2004), it was viewed by Chinese government as both a development opportunity and a challenge to the political order of socialist China (Ferdinand 2000; Longanecker 2009). The ambivalent attitude towards the Internet media in particular, and technology related products in general, has been reflected in the Chinese government's tremendous efforts in promoting the information and communication technology (ICT) development, while stringently controlling the Internet media. On the one hand, China's Internet infrastructure has been expanding quickly, with a penetration rate of over 44.1\% in 2013 (CNNIC 2013). The Chinese government has invested heavily in a fiber optic network that will significantly expand the reach of wired broadband in the near future. This investment is expected to increase the country's average broadband speed to 20 megabytes per second by the end of 2015 (Rapoza 2013). On the other hand, the Chinese government has maintained and even strengthened its strict controls on the Internet media and related products and services, based on its political ideologies. In terms of social platforms, the Chinese consumers had no access to certain popular social media sites (e.g., Facebook and Twitter): these contain politically sensitive information and have consequently been blocked by the government. This has created a form of digital divide between China and the rest of the world, despite the physical existence of ICT infrastructure ready for use (Lu 2001). In terms of gaming virtual worlds, arcade game rooms declined in popularity after 2000 , mainly because of government crackdown on 
gambling and illegal activities in the game rooms (Cao and Downing 2008). Likewise, while Wii, PS3 and Xbox 360 consoles are mostly assembled in China, video game consoles have been banned by Chinese government since 2000 (Ashcraft 2010).

\section{Continuous Constraints on Individualization and Hedonism}

Despite the changing economic and political circumstances, the older and established Chinese traditional sociocultural system nonetheless has an enduring influence on cultural conceptions of individuals. Even when confronted with the increased pressures of individualism and personal freedom (Yang and Neal 2006), the bedrock of Chinese culture would not change overnight, as "it takes time to construct the symbols and institutionalize them via processes of dissemination and socialization until they become dominant parts of the culture that is shared by at least the majority of society's members" (Schwarzer and Frensch 2012, p. 378). The Chinese society, as a whole, has not developed culturally to provide the individualization processes with the social support such trends require (Belk 2014). Rather, "there is an extensive negotiation among citizens, social structures and institutions on the one hand, and the logic of capital on the other" (Chu, Fortunati and Law 2012, p. 110). Indeed, the Chinese consumers, as individuals, must cope with the hard reality in Chinese society - persistence of traditional Chinese cultural values and of resistive forces from the social institutions such as the government, media, and family.

\section{Persistent Traditional Chinese Values}

Traditional Chinese values originated from Confucian cultural ethos (Jochim 1992; Yao 2000), which is a collectivist-based value system that emphasizes and glorifies collective interests over individual rights (Guo 2012). In China, which has long been a collectivist society (Fiske 2002), consumers are "we" oriented, their "self" identity is primarily an interdependent self that is based on the social system (Lu 2001) in which family interests are placed above those of individuals within it $(\mathrm{Wu}$ and Tseng 1985). The loyalty and piety to parents, and extended to employers and government officials, is highly valued (Liu 1986).

These cultural values have long lasting implications for consumption in the Chinese context, such as Chinese individuals' long valued self-control (Ho 1994), thriftiness, suppression of desire, delay in gratification through consumption (Pan et al. 1994), and emphasis on mian zi, or face, and guanxi, or social networks (Jap 2010). In addition, rather than use consumption by 'the independent self' for self-expression, those with an interdependent self-construal tend not to rely on objects for 
self-expression but to show similarity with their reference group (Aaker and Schmitt 2001).

Another source of persistence of traditions is the set of resistive forces emanating from three major social institutions: the government, the media, and the family.

1. Government: In an effort to fill the ideological vacuum left by the sidelining of Maoism (the form of Marxism-Leninism developed in China), a form of Confucianism has been glorified and championed by the Chinese government (Tse, Belk and Zhou 1989) as both a new national code of conduct, emphasizing the traditional values such as collectivism, self-control, harmony, thrift, industry, education; and as a symbol of national identity (Guo and Guo 2008). In 2006, at its sixth plenary session, the Sixteenth Chinese Communist Party Central Committee (CCPC) passed the policy of "Chinese Communist Party Central Committee's Resolution on Major Issues of Building a Socialist Harmonious Society" which covers not only political and economic institutions but also cultural dimensions (CCP 2006).

2. Media: Despite the increase in foreign brands in China since 1979, the local brands have continued to dominate and constitute the top advertisers (Kahn 2003), and have used more traditional values compared to foreign brands that use more modern values (Zhang and Harwood 2004; Zhao et al. 2013). Especially since 2006, there has been the increased use of collectivism appeal - individuals are portrayed as integral parts of the group and the emphasis is on the family tie (Cheng and Schweitzer 1996) - which illustrates the strong influence of local culture on consumer behavior (Zhao et al. 2013). Indeed, excessive use of global/western appeals in contemporary China may backfire and may cause audience confusion due to Chinese preference for local heroes and local values (Zhou and Belk 2004).

3. Family: The family has been a major arena for socialization of children, laying the foundation for their identity, as "parents were the primary source of children's exposure to their culture's language" (Maccoby 1992). Growing up in different circumstances characterized by frugality and collectivism, the Chinese parents, as trainers or transmitters of culture, passed down the traditional Chinese cultural values to the younger cohorts. In the meantime, they have high expectations for their only child to "maintain or improve their family's social position" 
(Stockman 2000, p. 112) and prepare them well, through education, for a society with fierce competition for limited social resources. The passed down collectivism-oriented cultural ideology, coupled with the high expectations and the responsibility as the only child to gain upward social mobility for the family, constituted the family environment of socialization for children, leaving little room for them for individualization. Anything that is not in line with the life project set by parents for their only children, such as online gaming, is deemed as time wasting and there have been reportedly numerous efforts to control the use of virtual worlds by the youth. In China, one dramatic and extreme case involved a father who hired an "online assassin" to kill his son's avatar in MMORGP repeatedly, hoping his son would give up playing (Lewis 2013).

\section{Discussion and Implications for Practice}

The narrative built in this paper places the issue of virtual goods market in the contemporary Chinese historical context, and provides a perspective of a larger place - reality as a whole (in which the virtual economy is embedded) - by documenting the continuous and discontinuous factors (economic, political/legal, sociocultural) that, interwoven together, condition virtuality and growth of virtual goods market in China.

The analysis showed, first, that the changes in China's economic landscape since 1979, when its economic reforms were initiated, have resulted in increased discretionary income and consumption power, expanded the set of consumption choices, and led to a proliferation of communication and information technologies and services that made Chinese consumer engagement in virtual goods markets possible. On the other hand, however, continuing unclear long-run prospects of China's economy have hindered the consumers' overall consumption desire and led to the high saving rate in China, which may have ripple negative effects on growth of virtual goods markets. Furthermore, the changes in the political landscape in China, such as those in the long-term policy of danwei (work unit), family planning, and ICT, have had positive impacts on consumer engagement in virtual goods markets: these factors have provided opportunities for the rise of individualization, concentrated financial resources for the only child in family, and developed a high-level Internet infrastructure. At the same time, the Chinese government's continuous political concerns towards Internet and unchanged stringent controls of Internet media have hindered the growth of virtuality and virtual goods markets. Also, the changes in sociocultural environment in China, 
such as rise of individualization and hedonism that came along with globalization, have had positive impacts on growth of virtuality and virtual goods markets: these symbolize the new electronic playgrounds and the "me" culture that appeal to the Chinese young consumers. By contrast, persistent Chinese traditional values (e.g., collectivism and the "we" culture) and constraints from social institutions such as government (e.g., Confucianism glorified and championed by government as national code of conduct), media (e.g., intensive media coverage of collectivism), and family (e.g., traditional values passed down from parents, high family expectation in real life for upward social mobility) have hindered the growth of virtuality and virtual goods markets.

Overall, the growth of the virtual goods markets provides Chinese consumers with access to the new consumption experiences and a greater range of resources for fun and experimenting with their identities. But the offline social "real" reality - shaped by old traditions and strict political regulation, especially of the media - still dominates and constrains the Chinese consumers' everyday lives and consumer behaviors. The predominant and long-persistent social ideology is still rooted deeply in the minds of the Chinese youth.

Slater (2002) argues that the dynamics of virtuality cannot be understood fully without an in-depth analysis of the reality such as political economy of access, material and symbolic power, and social conditions that structure the communication and sociality that go on inside virtual domains as well as in Real Life or RL. Many companies, however, have been focusing their efforts on designing immersive virtual worlds to engage the consumers, and paying little attention to $R L$, a bigger place that envelops virtuality and, in the case of China, creates conditions for certain types of virtuality to thrive while also thwarting other forms of virtuality. Grand Theft Auto is the best example here: this is a highly popular game in the western world was banned by the Chinese government when the game was introduced to China's market (Andre 2015). The implied criminality of the game was perceived by the Chinese authorities as not in line with the Chinese sociocultural values (Andre 2015; Nyhart 2012).

Thus, for the game-makers, virtual world creators, and virtual goods marketing firms, the major implication of reality in China, as a larger place that envelops virtuality, is that companies, in addition to paying attention to the usual virtual design elements, should also focus on the Chinese traditional cultural ideology that focuses on harmony and collectivism and the influences of Chinese social institutions such as government, family, and media. Also, it is important for firms to explore and locate consumers' 
wider experience of virtuality and virtual goods market in the context of the overall real life or $\mathrm{RL}$ context.

\section{Concluding Comments, Future Research}

The exploratory research work reported here was done with the backdrop of a China that has been experiencing radical changes over many decades. It is likely that such types of changes will continue in foreseeable future, but perhaps not into an indefinite future. The contemporary historic analysis of this paper can only apply to the particular period of time - the three-plus decades after 1979 - that was examined in some detail. As such, the ongoing changes in China's market, and the larger national context, need to be closely monitored and taken into consideration in future research. For example, the one-child policy has recently been abandoned and a new two-child policy just came into effect in 2015 (Xinhua 2015), and Chinese government has recently removed the ban that it had put on the manufacture and sale of videogame consoles since 2000 (CNN 2015). These changes will undoubtedly affect $R L$ as well as virtual markets.

Another research questions that is worth considering is how the Chinese consumers, living in the largest of virtual goods markets, navigate between their online virtual worlds and their offline worlds. One extreme end of the continuum of virtual consumption is the phenomenon of Internet addicts - "lost sense of place" (Meyrowitz 1985). China's Internet-virtual culture has been under criticism for being irresponsible and damaging to the psychological wellbeing of the Chinese consumers, but most the Chinese consumers appear to be able to navigate and strike an optimal balance between virtual worlds and the real-life worlds in which the virtual worlds are embedded. The specific ways of navigating and negotiating across these worlds by Chinese consumers will continue to be fertile arena for future research. 


\section{References}

Aaker, Jennifer and Bernd Schmitt (2001), "Culture-dependent assimilation and differentiation of the self: Preferences for consumption symbols in the United States and china", Journal of Cross-Cultural Psychology, 32 (5), 561-576.

Anderson, Michael (1984), Madison Avenue in Asia: Politics and transnational advertising, Madison $\mathrm{NJ}$ : Fairleigh Dickinson University Press.

Andre, Thibaud and DaxueConsulting (2015), "Video games in china: PC gaming still dominant?", DaxueConsulting, (accessed on Oct 16, 2015), [available at http://tech.co/video-games-china-pc-gamingstill-dominant-2015-07].

Ashcraft, Brian (2010), "Why Are Consoles Banned in China?", Kotaku: The Gamer's Guide, July 15, (accessed October 19, 2012), [available at http://goo.gl/Ohi02].

Barth, James, Michael Lea and Tong Li (2012), "China's housing market is a bubble about to burst?", Milken Institute, (accessed July 8, 2015), [available at: https://www.milkeninstitute.org/pdf/ChinaHousingMarket.pdf].

Becker, David (2004), "Online-game developers eye China market", CNET News, (accessed July 8, 2014), [available at: http://goo.gl/mCQQk].

Boykoff, Pamela (2010), "In virtual world, China consumers best the U.S", CNN, (accessed May 15, 2011), [available at http://www.cnn.com/2010/BUSINESS/03/15/china.virtual.economy/i ndex.html].

Bray, David (2005), Social Space and Governance in Urban China: The Danwei System from Origins to Urban Reform, Stanford CA: Stanford University Press.

Cao, Yong and John Downing (2008), 'The realities of virtual play: Video games and their industry in china', Media, Culture \& Society, 30 (4), 515-529.

CCP (2006), "Resolution by the Central Committee of the Chinese Communist Party concerning several important questions for Building a Harmonious Socialist Society", Chinese Communist Party, (accessed August 15, 2014), [available at qjc.peoplc.com.cn/BIG5/64162/]. 
Chan, Tsang-Sing, Geng Cui, and Nan Zhou (2009), "Competition between foreign and domestic brands: A study of consumer purchases in china", Journal of Global Marketing, 22 (3), 181-197.

Chayka, Kyle (2014), "Virtual Economies Are the Future of Consumption", Pacific Standard (accessed Nov 14, 2015), [available at https://psmag.com/virtual-economies-are-the-future-ofconsumption-7b290c79d867\#.7zwm48reh].

Chen, Jiangong (2009), "3D Virtual Worlds in China", Beijing Institute of Technology, (accessed March 9, 2013), [available at http://goo.gl/bz1ZG].

Cheng, Hong and John Schweitzer (1996), "Cultural values reflected in Chinese and U.S. television commercials", Journal of Advertising Research, 36 (3), 27-45.

Cho, Karen (2009), "KFC China's recipe for success", Insead, (accessed May 2, 2012), [available at http://knowledge.insead.edu/leadershipmanagement/strategy/kfc-chinas-recipe-for-success-1706].

Chu, Godwin and Yanan Ju (1993), The great wall in ruins: Communication and cultural change in china, Albany, NY: State University of New York Press.

Chu, Rodney Wai-chi, Leopoldina Fortunati, Pui-Lam Law (2012), Mobile Communication and Greater China, New York: Routledge.

CNN (2015), "China eliminates all restrictions on gaming consoles", CNN, (accessed August 1, 2015), [available at http://money.cnn.com/2015/07/27/technology/china-video-gameban-lifted/].

CNNIC (2013), "32nd Statistical Report on Internet Development", Beijing: China Internet Network Information Center, (accessed September 24, 2014), [available at http://www1.cnnic.cn/IDR/ReportDownloads/201310/P0201310294 30558704972.pdf].

deVries, Jan (2008), The Industrial Revolution: Consumer Behavior and the Household Economy, 1650 to the Present, Cambridge, UK: Cambridge University Press.

Dholakia, Nikhilesh, Ian Reyes, and Mann Zhang (2013), "Consumptionscapes and Markets in Virtual Worlds: Conceptual Framings", URI working paper series, University of Rhode Island. 
Dholakia, Ruby Roy (2012), Technology and Consumption: Understanding Consumer Choices and Behaviors, New York: Springer.

Fan, Chengze (2002), "Economic development and the changing patterns of consumption in urban China", in Beng-Huat Chua (ed,), Consumption in Asia: Lifestyles and Identities, London: Routledge.

Fang, Xiang and David Yen (2006), "An empirical study about the impacts of china's Accession to the WTO on the telecommunications industry in china", Journal of Organizational Computing and Electronic Commerce, 13 (1), 31-50.

Ferdinand, Peter (Ed.) (2000), The Internet, democracy and democratization (democratization studies), London: Frank Cass Publishers.

Fiske, Alan Page (2002), "Using individualism and collectivism to compare cultures--a critique of the validity and measurement of the constructs: Comment on Oyserman et al (2002)", Psychological Bulletin, 128 (1), 78-88.

Friedman, Milton and Rose Friedman (1980), Free to choose: a personal statement, New York: Harcourt Brace Jovanovich.

Guo, Sujian (2012), Chinese Politics and Government: Power, Ideology and Organization, London: Routledge.

Guo, Sujian and Baogang Guo (2008), China in Search of a Harmonious Society, Lexington MA: Lexington Books.

Hawkins, Trip (2012), "A Browser manifesto- Part 7: It's not a prediction, It's already happening in Asia", Trip's OMG Blog, (accessed August 9, 2013), [available at http://goo.gl/KDUJk].

Hill, Richard Child (2005), "Review of Bray, David, social space and governance in urban china: The Danwei system from origins to urban reform", H-Review, (accessed October 6, 2015), [available at https://www.h-net.org/reviews/showrev.php?id=10772].

Ho, David (1994), "Filial piety, authoritarian moralism, and cognitive conservatism in Chinese societies", Genetic, Social, and General Psychology Monographs, 120, 347-365.

Hobsbawm, Eric (1997), On History, New York: The New Press.

Ikels, Charlotte (2006), "Economic reform and intergenerational relationships in china", Oxford Development Studies, 34 (4), 387400. 
Jap, Warveni (2010), "Confucius Face Culture on Chinese Consumer Consumption Values toward Global Brands", Journal of International Management Studies, 5 (1), 183-192.

Jochim, Christian (1992), "Confucius and Capitalism: Views of Confucianism in Works on Confucian Ethics and Economic Development", Journal of Chinese Religion, 20, 135-171.

Kahn, Gabriel (2003), “Local brands outgun foreigners in China's advertising market", Wall Street Journal (Eastern edition), 8, October 1.

Kwang Kevin (2011), "Online games, social networks drive virtual goods", ZDNET, (accessed July 12, 2012), [available at http://www.zdnet.com/article/online-games-social-networks-drivevirtual-goods/].

Leung, Man and Ricky Chan (2006), "Are foreign banks sure winners in post-WTO china?", Business Horizons, 49 (3), 221-234.

Lewis, Helen (2013), "Think your kids spend too long playing video games? Don't hire an assassin", The Guardian, (accessed October 10, 2015), [available at http://www.theguardian.com/commentisfree/2013/jan/08/videogames-assassin-addiction].

Lieberthal, Kenneth (1995), Governing china: From revolution through reform, New York: W. W. Norton \& Co.

Lin, Xiaohua and Cheng Lu Wang (2010), "The heterogeneity of Chinese consumer values: A dual structure explanation", Cross Cultural Management: An International Journal, (A. Kai Ming AU, ed.), 17 (3), 244-256.

Liu, William (1986), "Culture and social support", Research on Aging, 8, 57-83.

Longanecker, Mindy Kristin (2009), "No Room for Dissent: China's Laws Against Disturbing Social Order Undermine Its Commitments to Free Speech and Hamper the Rule of Law", Pacific Rim Law \& Policy Journal, 18 (2), 373.

Lu, Mingte (2001), "Digital divide in developing countries", Journal of Global Information Technology Management, 4 (3), 1-4. 
Maccoby, Eleanor (1992), "The role of parents in the socialization of children: An historical overview", Developmental Psychology, 28 (6), 1006-1017.

Meyrowitz, Joshua (1985), No Sense of Place: The impact of electronic media on social behavior. Oxford UK: Oxford University Press.

Morrison, Wayne M. (2012), "China's Economic Conditions", Congressional Research Service, (accessed Aug 7, 2013), [available http://fpc.state.gov/documents/organization/194783.pdf].

Morrison, Wayne M. (2015), "China's Economic Rise: History, Trends, Challenges, Implications for the United States", Congressional Research Service, (accessed Oct 14, 2015), [available at https://www.fas.org/sgp/crs/row/RL33534.pdf].

NDC China (2009), China's Virtual goods market, Shanghai, China.

Niko Partners (2010), "Niko Partners Estimates China's Online Game Market to reach $\$ 9.2$ billion in 2014", Niko Partners Press Release, (accessed March 31, 2012), [available at http://goo.gl/s4M0G].

Nyhart, Peter (2012) 'China set to launch video game console...for 600 Bucks', The Jace Hall Show: Game Culture and Lifestyle, (accessed June 27, 2013), [available at http://goo.gl/j8056].

Ogden, Suzanne (1995), China's Unresolved Issues: Politics, Development and Culture, Englewood Cliffs NJ: Prentice Hall.

Pan, Zhondang, Steven H. Chaffee, Godwin C. Chu and Yannan Ju (1994), To See Ourselves: Comparing Traditional Chinese and American Cultural Values, Boulder CO: Westview Press.

Perez, Bien (2015), "China has more smartphone users than US, brazil, and Indonesia combined", Business Insider, (accessed August 6, 2015), [available at http://www.businessinsider.com/china-hasmore-smartphone-users-than-us-brazil-and-indonesia-combined2015-7].

Rao, Leena (2015), “Alipay's US chief talks expansion, Uber china partnership and more", Fortune, (accessed November 6, 2015), [available at http://fortune.com/2015/06/19/alipay-china-uberalibaba/]. 
Rapoza, Kenneth (2013), "China says broadband speeds of 20 Mbps by 2015", Forbes, (accessed Feb 3, 2014), [available at http://www.forbes.com/sites/kenrapoza/2013/08/18/china-saysbroadband-speeds-of-20-mbps-by-2015/].

Raquel Castaño, Rajagopal (2015), Understanding consumer behavior and consumption experience, Hershey, PA: IGI Global.

Ren, Qun and Xiaosong Yang (2004), "Analysis of the development of Chinese online game industry", Wuala (cloud storage), (accessed August 16, 2013), [available at http://goo.gl/PB9gH].

Rosen, Stanly (2004), "The victory of materialism: aspirations to join China's urban moneyed classes and the commercialization of education", The China Journal, 51, 27-51.

Schwarzer, Ral and Peter A. Frensch (2012), Personality, Human Development, and Culture: International Perspectives on Psychological Science, Hove UK: Psychology Press.

Slater, Don (2002), "Social relationships and identity online and offline", In: L. Lievrouw \& S. Livingstone (Eds), The Handbook of New Media. London: Sage, 534-547.

Statista (2012), "Estimated revenue of virtual goods sales in china from 2006 to 2010 with forecast until 2013 (in million U.S. Dollars)", Statista, (accessed June 24, 2015), [available at http://www.statista.com/statistics/269323/sales-of-virtual-goods-inchina/].

Stockman, Norman (2000), Understanding Chinese society, Cambridge UK: Polity Press.

Su, Susan (2010), "China: Virtual goods are big, social games are still growing", SocialTimes, (accessed May 6, 2012), [available at http://www.adweek.com/socialtimes/china-virtual-goods-are-bigsocial-games-are-still-growing/566474].

Trading Economics (2015), "China Disposable Income per Capita", Trading Economics, (accessed Oct 19, 2015), [available at http://www.tradingeconomics.com/china/disposable-personalincome].

Tse, David, Russell Belk and Nan Zhou (1989), "Becoming a consumer society: A longitudinal and cross-cultural content analysis of print ads from Hong Kong, the people's Republic of China, and Taiwan", Journal of Consumer Research, 15 (4), 457-472. 
Warschauer, Mark (2004), Technology and Social Inclusion: Rethinking the Digital Divide, Cambridge MA: MIT Press.

Wei (2014), "China has 517 Million Gamers; MMO market surpassed \$9.7 Billion revenue", $2 P$, (accessed November 6, 2015), [available at http://2p.com/16612894_1/China-Has-517-Million-Gamers-MMOMarket-Surpassed-97-Billion-USD-Revenue-by-Wei.htm].

Woronov, Terry (2004), "In the eye of the chicken: Hierarchy and marginality among Beijing's migrant schoolchildren", Ethnography, 5 (3), 289-313.

Wu, David Y.H. and Wen-Shing Tseng (1985), "Introduction: The characteristics of Chinese culture", In W. Tseng \& D. Y. H. Wu (Eds.) Chinese Culture and Mental Health, 3-13.

Xinhua (2015), "China to allow two children for all couples", Xinhuanet, (accessed Nov 1, 2015), [available at http://news.xinhuanet.com/english/2015-10/29/c_134763507.htm].

Yang, Fenggang (2005), "Lost in the market, saved at McDonald's: Conversion to Christianity in urban China", Journal for the Scientific Study of Religion, 44 (4), 423-441.

Yang, Renxin and Arthur Neal (2006), "The impact of globalization on family relations in China", International Journal of Sociology of the family, 32 (1), 113-126.

Yao, Xinzhong (2000), An introduction to Confucianism, New York: Cambridge University Press.

Yu, Haiqing (2009), Media and cultural transformation in China, New York: Routledge.

Zhang, Xi, Douglas Vogel and Zhenjiao Chen (2010), "Understanding the 3D virtual world market in china: A comparative case study of $\mathrm{HiPiHi}$, Uworld and Novoking", 2010 2nd IEEE International Conference on Information Management and Engineering. April 1618, Beijing.

Zhang, Yanbing and Jake Harwood (2004), "Modernization and tradition in an age of globalization: Cultural values in Chinese television commercials", Journal of Communication, 54 (1), 156-172. 
Zhao, Miao, Ruby R. Dholakia, Zhen Cai, and Man Zhang (2013), "An Empirical Investigation of Chinese Award-Winning TV Advertisements over Time," International Journal of China Marketing, 3 (2), 100-117.

Zhou, Nan and Russell Belk (2004), "Chinese consumer readings of global and local advertising appeals", Journal of Advertising, 33 (3), 6376. 